\title{
Vietnamese EFL Teachers' Classroom Assessment Practice at the Implementation of the Pilot Primary Curriculum
}

\author{
Pham Thi Nguyen Ai*, Nguyen Vu Quynh Nhu, Nguyen Ho Hoang Thuy \\ Department of English, University of Foreign Languages, Hue University, Hue City, Vietnam \\ Email address: \\ ptnguyenai@hueuni.edu.vn(P. T. N. Ai),nvqnhu@hueuni.edu.vn(N.Vu Q. Nhu),nhhthuy@hueuni.edu.vn(N. Ho H. Thuy) \\ ${ }^{*}$ Corresponding author
}

\section{To cite this article:}

Pham Thi Nguyen Ai, Nguyen Vu Quynh Nhu, Nguyen Ho Hoang Thuy. Vietnamese EFL Teachers' Classroom Assessment Practice at the Implementation of the Pilot Primary Curriculum. International Journal of Language and Linguistics. Vol. 7, No. 4, 2019 , pp. $172-177$. doi: $10.11648 /$ j.ij11.20190704.15

Received: May 7, 2019; Accepted: June 27, 2019; Published: July 23, 2019

\begin{abstract}
With the launch of the National Foreign Language 2020 Project, the Vietnamese Ministry of Education and Training (MOET) has introduced a pilot English curriculum for the primary educational level, which aims to help primary school pupils achieve level A1 in the Common European Framework of Reference for Languages (CEFR). The implementation of the new curriculum requires major change in teaching methodology, teaching materials and classroom assessment. A new textbook series has also been developed in alignment with the pilot curriculum. Methodology training workshops have been provided so as to facilitate the process of implementing the new curriculum and textbooks. Classroom assessment training curriculum developed in accordance with the pilot curriculum has been delivered to key primary English language teachers. This study reports our investigation into changes teachers have made in their assessment practice on the implementation of the pilot primary English language curriculum. The research involves 67 teachers of primary schools implementing the new curriculum. Data are collected by means of teachers' in-depth interview and assessment samples. The findings have shown that the investigated teachers have made effort to change their assessment practice so as to facilitate the new curriculum. However, there are still a number of contextual and perceptual factors interfering with the process of changing the assessment practice.
\end{abstract}

Keywords: Primary, English, Assessment, Perception, Curriculum

\section{Introduction}

\subsection{Assessing Young Language Learners}

Assessment has always played a crucial role in education. In language instruction, where progress in the language performance of students tends to develop over a long period of learning and instruction time, language assessment, if properly implemented, can provide valuable information about student learning for teachers to improve their teaching in a timely manner, and so helps enhance learning outcomes. Literature on assessment for young language learners has indicated that extra care, preparation and support are required for successful implementation of language assessment tasks and techniques so as to encourage young language learners to continue to learn. The following principles have been generally agreed in literature on assessing young language learners [1-4]. First and foremost, language assessment needs to be oriented towards age-related abilities. That is, it should be responsive to the levels of physical, emotional and cognitive growth of a specific age group. Second, language assessment should be personalised, captivating, engaging and game-like to maintain YLLs' interest. Thirdly, language assessment needs to cater all levels of achievement, allowing flexibility in evaluation and passes for all at different levels. Fourthly, topics and input provided in language assessment should be associated with familiar, simple subjects or topics used in everyday communication to make young language learners feel "psychologically safe" and comfortable. Input provided should be simple, well-illustrated with images, verbal cues, and examples of expected responses. Fifthly, language assessment should focus on what young language learners can do, rather on what they cannot do so as to encourage them to learn, and feel successful and motivated. Sixthly, support needs to be made available so as to encourage young language learners to complete language assessment 
tasks, especially in oral skill assessment as well as to keep them on track. Finally, immediate feedback for language assessment task performance is very important to help young language learners maintain attention, concentration and confidence.

These imply that when assessing the language abilities of young language learners, extra care, support, preparation, devotion, and expertise in assessment as well as knowledge of child development are required on the part of teachers as language assessors. Research on primary school teachers' assessment on the other hand has shown that teachers mostly understand the significance of formative assessment [5-6] and tend to associate assessment for young learners with controlled classroom tasks, oral and portfolio assessment [6-7] but they believe that it is time-consuming and not as effective as traditional tests used in summative assessment in assessing students' language skills [8].

\subsection{The Introduction of the Pilot Primary English Language Curriculum and Assessment Policy}

Together with the initial introduction of English as an elective subject at primary school in the early 1990s with little guidance on its assessment, and then the introduction of the new English curriculum on a nationwide scale in 2009, the status of English in the primary school programme has changed remarkably and the English language assessment policy by the Ministry of Education and Training (MOET) has also evolved over time. Decision No. 50/2003 by the MOET provides general, primary guidance for English assessment for primary school pupils as follows: "Testing and assessment should strictly follow the objectives, content and the required standard regarding English language knowledge and skills and must involve all listening, speaking, reading and writing skills; assessment must be based on test scores and participation evaluation; frequent assessment [formative] and scheduled assessment [summative] must be combined" (p. 9) [9]. Since then, little else on assessing young language learners can be found and, as Moon remarked, guidelines provided by the MOET were not specific enough in the case of Vietnam where the educational system suffers from a lack of expertise in English language education at primary level [10].

Decision 1400 of the Vietnamese government, dated 30 September 2008 approved the national project titled "Teaching and learning foreign languages in the national educational system for 2008-2020 period" (commonly referred to as Project 2020). Among the many objectives related to foreign language teaching and learning set by Project 2020, foreign languages are planned to be a compulsory subject in the new 10-year foreign language learning programme, starting from grade 3, then 4 and 5 of primary education and continuing up to grade 12 of high school education. The implementation of a new foreign language curriculum, mainly focused on English, on a nationwide scale is planned to be completed in three consecutive phases. First, from 2010-2011, the objective was to have $20 \%$ of primary students learn a foreign language with the numbers being expanded to $70 \%$ by $2015-2016$ and $100 \%$ by 2018-2019. Decision 1400 also sets level A1 in the Common European Framework of Reference for Languages (CEFR) as the standard learning outcome required of all students graduating from primary schools [11].

Regarding the assessment policy for primary school pupils, six years after the launch of Decision No. 50 in 2003 and one year after the launch of Decision No. 1400 in 2008, MOET introduced Circular No. 32, dated 27 October 2009, providing further guidance on the testing and assessment of primary pupils' learning performance in all subjects covered by the national primary curriculum, including foreign languages. Circular No. 32 is the very first document from the MOET to provide more substantial guidance, though it is still insufficient in specifying how primary students should be assessed on their foreign language learning. This document maintains that "assessment is a frequent activity by the teacher and when assessing students, the teacher needs to pay attention to students' progress and end-of-year assessment [summative] is most important" (emphasis added) (p. 4) [12]. Circular No. 32 introduces two types of assessment: formative and summative and describes oral assessment and written tests of less than 20 minutes as formative assessment while describing summative assessment as being by end-of- $1^{\text {st }}$-semester tests and end-of-academic-year tests. Formative assessments must be carried out at least once a month and summative assessments twice a year by means of the two tests (oral and written). According to Circular No 32, teachers are requested to report their students' foreign language learning performance on a scale out of 10 marks accompanied by the teacher's comments on pupils' progress and performance.

In 2010, MOET produced Decision No. 3321/QD-BGDDT, dated 12 August 2010, regarding the official launch of the primary English curriculum, which was designed following the direction of Decision No. 1400 and the objectives of the Project 2020 [13]. English for grades 3, 4, 5 [14], the three-volume primary English textbook series were soon developed on the basis of this new curriculum and piloted with 4 x 40-minute language class periods each week, starting with English for grade 3 in 2010-2011, English for grade 4 in 2011-2012, and English for grade 5 in 2012-2013.

To help the teachers, who taught English for grade 3 and grade 4 , to carry out the assessment work for primary students who participated in the pilot English programme, in December 2011, MOET organised 2 x 2-day workshops, one in Hanoi City and one in Ho Chi Minh City for key primary teachers using the pilot textbook programme in 63 provinces and municipal cities to be trained on how to design language tests for classroom assessment [15]. In the same month, Dispatch No. 9749/BGDDT-GDTH from the MOET, dated 29 December 2011, provided more specific guidelines on the implementation of summative assessment for grade 3 and grade 4 students [15]. In March 2012, MOET issued Dispatch No. 1237, dated 6 March 2012, enforcing the reviewing and evaluating of the implementation of the pilot English [16].

Later MOET launched Dispatch No. 3032, dated 9 May 2013, providing guidance on end-of-academic-year 
assessment work for grades 3, 4 and 5 for the school year 2012-2013 [17]. It again provided a specific format for grades 3,4 and 5 with the format of Listening and Speaking being the same for all grades and slight changes for Reading and Writing between grades 3, 4 and 5. A test sample was also provided. For the academic year 2013-2014, no further guidance on English language assessment for primary students was given, except that the MOET launched Dispatch No. 5478, dated 8 August 2013, which stated that the English language testing and assessment for primary pupils should follow the guidance provided in Dispatch No. 3032 launched and applied for the previous academic year, 2012-2013 [18]. Since then a classroom assessment training curriculum for in-service teachers has been developed. This training curriculum has 5 main modules, covering the description of the required learning outcome of the pilot curriculum, the relation between the required learning outcome and assessment, major principles in assessing young language learners, methods and techniques of assessment, and feedback delivering techniques, and how to use information collected from assessment. Key primary school teachers from different provinces where the English language curriculum is piloted have been trained.

\subsection{Primary English as a Foreign Language (EFL) Teachers in Vietnam}

A large number of EFL teachers, at all educational levels including those teaching English in primary schools in Vietnam, have a low level of English proficiency [19-25]. Although a majority of them were trained to become teachers of English, some of them were formerly trained to teach Russian and then retrained intensively to teach English [20, 26]. Most, if not all, of them are not formally trained to teach English to young learners [27] because the first cohort of university students majored in primary English teacher training programme did not graduate until July 2013 [22].

Within the current English instruction context in Vietnam, where a majority of teachers of English are below the required language proficiency standard, lacking adequate training both in language teaching methodology and assessment, facing various issues ranging from professional to school culture [22], research on the impact of the implementation of the pilot curriculum on teachers' assessment will provide an understanding of their practice and information for innovations in in-service teacher training curriculum.

\section{The Study}

\subsection{Research Questions}

The current paper seeks to address the following research questions:

1. What is EFL primary school teachers' assessment practice at the implementation of the pilot English language curriculum?

2. What problems do they face regarding classroom assessment since the introduction of the pilot curriculum?

\subsection{Participants}

The participants of this research are 67 primary English teachers teaching at schools implementing the new pilot curriculum in Central provinces in Vietnam. These teachers have from one to seven years of experience in teaching English at primary schools. None of them have received formal training in the methods of teaching English to primary school pupils during their first degree.

\subsection{Research Instruments}

This study employed the following instruments to collect data relevant to the research questions: in-depth interview and an accumulated corpus of assessment samples including summative test papers and formative assessments in various formats and of different lengths.

A corpus of 123 assessment samples, mainly actual tests were collected from 67 investigated teachers. In-depth interviews were conducted with 12 teachers. Average length of interview duration was 30 minutes. Interviews were used to explore further the reasons underlying the participants' assessment practice.

\section{Findings and Discussions}

A careful analysis of the collected test corpus and interview data was carried out.

Our analysis of the test corpus and interview data has shown the following trends.

First, the most popular assessment form used by the participants is tests, different in terms of volume and length. Other form of formative assessment such as portfolio and learning diary, which have been proved to be effective in young language learner assessment, are not systematically or properly used. That is although interview data show that a few teachers do use "portfolios", these are actually a collection of short written tests accumulated and recorded by learners. Primary teachers administer one 35-minute test a month for formative purpose, totalling eight formative tests a year. Summative tests are often one end-of- $1^{\text {st }}$-semester large-scale test and one end-of-academic-year large-scale test designed and distributed by the provincial Department of Education and Training (DOET). The same assessment practice is required for both groups of students, those learning 4 x 35-minute periods a week with the pilot textbook series and those learning 2 or $3 \times 35$-minute periods a week with books published by other publishers, commonly Let's go and Family and Friends by Oxford University Press. In all formative test samples collected, all four language skills are provided. However, interview data show that speaking assessment is not practised. The summative end-of-semester/year tests also cover all language skills and are administered on the same day, at the same time (except for the speaking test) for all students in the same grade (i.e. for fourth and fifth graders) within each province. Speaking is assessed by the teacher before or after 
the large-scale test administration.

A scrutiny of the test corpus shows that, although examples of the expected responses and different forms of support, such as either verbal or visual cues (images) are provided, most, if not all items of the collected formative tests are selected-response items.

A strong impact on teachers' development and use of formative tests can be observed following the format of the summative assessment guide, provided by the MOET, and the summative tests designed by the DOETs. Many test tasks and items in the formative tests mimic the summative large-scale test items used by the DOETs. This shows that more attention to the impact of the implementation of standardised summative tests on teaching and learning process needs to be taken into consideration, given that the quality of a test is associated not just with its psychometric traits but also with its impact, fairness, values, ethicality and consequences [28-29]. It is perhaps not surprising that teachers may feel forced to engage in "test-like" materials. Shohamy highlights examples where the introduction of new assessment tasks in national tests influenced teachers' choice of teaching materials and also curriculum: instead of teaching language skills in integrated ways, the teachers shifted to the use of texts and multiple-choice questions as well as oral speaking tasks which are similar to those included in the national tests [30]. While this style of assessment may have a cultural basis in Asian contexts [31], the use of test-like assessment as formative assessment practice, however does not support assessment for learning [32]. While some research is now starting to investigate the impact of classroom assessment on teachers who are required to report against standards and to prepare children for large-scale tests tied to standards [2], literature on primary language teachers' assessment has shown that teachers can become stressed and resentful at the time taken in assessment and paperwork, and there is also evidence that YLLs find it stressful as they are prepared for large-scale tests through mini practice paper-based tests in the classroom [3].

Both interview data and examination of test samples show that basically the primary teachers in the sample do not design tests. They adopt test items from English practice tests from module books by different publishers. The textbooks in use are not well-suited to primary school students in terms of their grammar-oriented focus, activities and input types [19]. This leads to the dominance of book series published by international publishers [10] over the MOET series piloted in schools, particularly where there is the option for schools to choose textbooks rather than using the piloted series by the MOET. However, teachers do find the materials published by other publishers, especially Cambridge young language learner series including Starters and Movers, helpful sources for use in formative assessments. However, as pointed out above, their preference for selected-response items, grammar knowledge and memorisation items, as shown in the collected test corpus, suggests that the feedback from assessment, mainly in the form of test scores is not really helpful in providing information about students' language skill performance.

The primary teachers in the sample make little use of assessment feedback. On the one hand, their formative assessment, mainly in the form of monthly 35-minute tests, usually scored by peers with correct answers provided by the teachers for each task and no further comment or feedback, is often returned to the students with a score, limited corrective feedback and little else. Some teachers report that they provide one-off, general, oral comments on students' performance on the test for the whole class but do not have the chance to make assessment and assessment feedback more personalised. Interview participants also report keeping a record book of students' performance across reading, writing and listening skills (score) from monthly formative tests. On the other hand, the comments they provide on students' English learning are also limited. At the end of the first semester, together with other subjects, usually English comes up in students' academic report with just a score from the summative end-of-semester test. At the end of the academic year, English is recorded in the academic report also with a score and a general comment, usually in the form of ranking (i.e., good, fair, and so on). Although English teachers of grade 3 have more flexibility, because grade 3 students do not have to take any summative (end-of-semester or academic-year) large-scale test, the method of providing feedback on students' performance is little different.

The participants report little change in teaching as a consequence of assessment results. Among major reasons quoted are large class sizes, full curriculum and heavy workload. Each class at primary school level has between 28 and 45 pupils. However, for all primary schools in the urban areas of the provinces surveyed, no class had fewer than 40 students, despite the MOET policy of having foreign language classes of less than 35 students each. The curriculum with the pilot textbook series, mostly for grade 4 and 5 is said to be too dense, having too wide a vocabulary and grammar coverage to be taught properly within the time allocated. To make matters worse, teachers are often assigned a heavy teaching load. Despite the MOET policy of assigning primary school teachers 16-18 teaching hours per week, the average number of hours primary school teachers are asked to teach a week is 25 hours (each "teaching hour" for primary school student is usually 35 to 40 minutes). In many cases this number goes up to 29 [22], and even 33 from week 5 to week 12 for some teachers as they need extra four hours for preparing more competent students for English tests and competitions at city, provincial and national levels.

The findings on teacher assessment practices have indicated the tension or difference between what they know they should do when assessing young language learner and the actual assessment they undertake in their practice. This is not something new in the literature on assessment as it is often the case that such a tension shows the ubiquitous discrepancy between the conditions for assessment to be undertaken properly and the actual teaching and learning conditions [33]. 


\section{Conclusion}

The preliminary findings of the present study have shown major issues in the process of bringing evaluation, assessment policy and language assessment practices into alignment. In countries like Vietnam, where the MOET takes full responsibility for all of the planning, designing the curriculum and producing or choosing the instructional materials as well as providing assessment policy, and even summative large-scale tests, research should be conducted on a national scale to explore further and gather information about teachers' perceptions of assessment and their practice in addition to the impact of summative assessment on learners, especially on young language learners. Baldauf, Kaplan, Kamwangamalu, and Bryant identify twelve fundamental reasons which may lead to failure of primary English language planning [34]. We realize that in the case of Vietnam, the first eleven of these twelve reasons may be closely associated with language assessment implementation. These reasons may include: time dedicated to language assessment is inadequate; indigenous teacher training on assessment is not appropriate nor sufficient; the myth that native speakers as well as foreign assessment materials can fill non-native teachers' low language proficiency and lack of expertise in assessment; educational materials such as textbooks may not facilitate the set learning outcome standards and the implementation of assessment aligned to those standards; assessment methods may not support the expected learning outcomes; resources may be inadequate or may not facilitate language assessment; continuity of stakeholders', especially teachers' commitment in implementing proper language assessment, may be short-term and problematic; language norms in assessment may be a problem, for example British English being set as standard for English textbooks in use but no guidance or instruction on which standard English is assessed either in formative and summative assessment; international donor-funded teacher-training assessment training, or foreign assessment models may not be relevant or feasible at implementation level; primary school children may not be properly prepared for early language instruction and they may feel the same towards summative assessment; and assessment practice may not actually meet community and/or national objectives.

\section{Implications}

Attempts to implement a successful language assessment policy in alignment with the pilot curriculum require comprehensive reform efforts for improvements to teacher training and development, to curriculum alignment and coherence, for preparing instructional materials and for developing better language methodology. For effective school-based assessment implementation, teachers need to be well-prepared in order to be able to make use of assessment techniques to improve student learning and learning outcomes, and to adapt their own teaching. Inadequate training, a lack of expertise in language assessment and a lack of coherence between assessment and method or between assessment and defined learning objectives will lead to failure in primary language education, making language planning policies appear to be predominantly political [34-35] and leading to massive failures and unfortunate waste of resources $[34,35]$.

\section{References}

[1] Hasselgreen, A. Assessing the language of young learners. Language Testing. Vol. 22, No. 3, 2005, pp. 337-354.

[2] McKay, P. Do standards have something to answer for? A pedagogic response to standards. Plenary Address. TESOL Arabia. Dubai. March, 2004.

[3] McKay, P. Assessing young language learners. Cambridge: Cambridge University Press, 2006.

[4] Menken, K., Hudson, T., \& Leung, C. Language assessment in standards-based education reform. TESOL Quarterly, Vol. 11, No. 3, 2014, pp. 586-614.

[5] Yang, T. Factors affecting EFL teachers' classroom assessment practices with young language learners. Unpublished Doctoral thesis. The University of Iowa, USA, 2007.

[6] Brown, G. T. L. Teachers' conceptions of assessment: Implications for policy and professional development. Assessment in Education. Vol. 11, No. 3, 2004, pp. 301-318.

[7] Dunn, K., Strafford, E., \& Marston, C. Classroom assessment practices in English and mathematics at year 5, 7 and 9. Unpublished BA thesis. Wellington, New Zealand, 2003.

[8] Al-Nouh, N. A., Taqi, H. A., \& Abdul-Kareem, M. M. EFL primary school teachers' attitudes, knowledge and skills in alternative assessment. International Education Studies. Vol. 7, No. 5, 2014, pp. 68-84. doi: 10.5539/ies.v7n5p68.

[9] MOET. Primary English-as-an-elective-subject curriculum Issued together with Decision No. 50/2003/BGDDT by the Minister of MOET, dated 30 October, 2003. Hanoi.

[10] Moon, J. The teacher factor in early foreign language learning programme: The case of Vietnam. In M. Nikolov (Ed.), The age factor and early language learning (pp. 311-336). Berlin: Mouton de Gruyter, 2009.

[11] MOET. Decision No. 1400/QD-TTg Approval of the Project "Teaching and learning foreign languages in the national educational system for the 2008-2020 period". Hanoi, 2008.

[12] MOET. Circular No. 32/BGDDT-TT Regulations of assessment and ranking for primary school students. Hanoi, 2009.

[13] MOET. Decision No. 3321/QD-BGDDT-Ref: Launching pilot primary English language curriculum. Hanoi, 2010.

[14] Hoang, V. V., Phan, H., Do, T. N. H., Dao, N. L., Truong, T. N. M., \& Nguyen, Q. T. English for grade 3, 4, 5. Hanoi: Education Publishing House, 2010, 2011, 2012.

[15] MOET. Dispatch No. 9747/BGDDT-GDTH-Ref: Guidance on end-of- ${ }^{\text {st }}$-semester testing and assessment of English for grade 3 and grade 4 - academic year 2011-2012. Hanoi, 2011.

[16] MOET. Dispatch No. 1237/BGDDT-GDTH-Ref: Reviewing and evaluating the implementation of the pilot primary English curriculum and the implementation of large-scale English language instruction at primary level. Hanoi, 2012. 
[17] MOET. Dispatch No. 3032/BGDDT-GDTH-Ref: Guidance on end-of-academic-year testing and assessment of English for grade 3, 4 and 5-academic year 2012-2013. Hanoi, 2013.

[18] MOET. Dispatch No. 5478/BGDDT-GDTH-Ref: Guidance on primary education for the academic year 2013-2014. Hanoi, 2013.

[19] Moon, J. Investigating the teaching of English at primary level in Vietnam: A summary report. Paper presented at the conference on the Teaching English Language at Primary Level. Hanoi, 2005.

[20] Ha, V. S. Is grade 3 too early to teach EFL in Vietnam? In M. L. McCloskey, J. Orr \& M. Dolitsky (Eds.) Teaching English as a foreign language in primary school (pp. 111-122). Illinois, USA: TESOL Inc, 2006.

[21] Nguyen, T. M. H., \& Nguyen, Q. T. Teaching English in primary schools in Vietnam: An overview. Current Issues in Language Planning. Vol. 8, No. 1, 2007, pp. 162-173.

[22] Pham, T. H. N. Obstacles to primary school teachers' implementation of methodological innovations to teach English to young learners. Hue University Journal of Science. Vol. 80, No. 2, 2013, pp. 35-46.

[23] Nguyen, H. T. A. Pilot intensive programme in Ho Chi Minh city: A programme that meets the needs of society. In L. Grassick (Ed.), Primary innovations regional seminar: $A$ collection of papers (pp. 113-116). Hanoi: British Council Vietnam, 2007.

[24] MOET Report. Project 2020 Report. Proceeding of National Conference on the Effect of In-service EFL Teacher Training (pp. 1-10). Quy Nhon, Vietnam, November, 2013.

[25] Pham, T. H. N. General English proficiency or English for teaching? The preferences of in-service teachers. RELC Journal. Vol. 49, No. 3, 2018, pp. 339-352.

[26] Le, V. C. A historical review of English language education in Vietnam. In Y. H. Choi \& B. Spolsky (Eds.), English education in Asia: History and policies (pp. 1013-1034). Seoul: Asia TEFL, 2002.

[27] Nguyen, T. M. H. Primary English language education policy in Vietnam: Insights from implementation. Current Issues in Language Planning. Vol. 12, No. 2, 2011. doi: 10.1080/14664208.2011.597048.

[28] Shohamy, E. Language tests as language policy tools. Assessment in Education: Principles, Policy and Practice. Vol. 14, No. 1, 2007, pp. 117-130.

[29] Shohamy, E. Language policy and language assessment: The relationship. Current Issues in Language Planning. Vol. 9, No. 3, 2008, pp. 363-373.

[30] Shohamy, E. The power of tests: A critical perspective on the uses of language tests. Harlow, UK: Pearson Education, 2001.

[31] Kennedy, K., Chan, J. K. S., Yu, W. M., \& Fok, P. K. Assessment for productive learning: Forms of assessment and their potential for enhancing learning. Paper presented at the $32^{\text {nd }}$ Annual Conference of the International Association for Educational Assessment, May 21-26, Singapore, 2006.

[32] Gipps, C. Round table on school-based assessment: Discussant presentation. Paper presented at the International Association for Educational Assessment (IAEA) Annual Conference, September 1-6, Hong Kong, 2002.

[33] Webb, M. E., \& Jones, J. Exploring tensions in developing assessment for learning. Assessment in Education: Principles, Policy \& Practice. Vol. 16, No. 2, 2009, pp. 165-184.

[34] Baldauf, R. B., Kaplan, R. B., Kamwangamalu, Nk., \& Bryant, P. Success or failure of primary second/foreign language programmes in Asia: What do the data tell us? Current Issues in Language Planning. Vol. 12, No. 2, 2011, pp. 309-323.

[35] Kaplan, R. B., \& Baldauf, R. B. Language-in-education policy and planning. In E. Hinkel (Ed.), Handbook of research in second language teaching and learning (pp. 1013-1034). Mahwah, NJ: Lawrence Erlbaum Associates, 2005. 